\title{
Smokeless tobacco use in Pakistan and its association with oropharyngeal cancer
}

\author{
K.M. Bile, ${ }^{7}$ J.A. Shaikh, ${ }^{1}$ H.U.R. Afridi ${ }^{1}$ and Y. Khan ${ }^{2}$
}

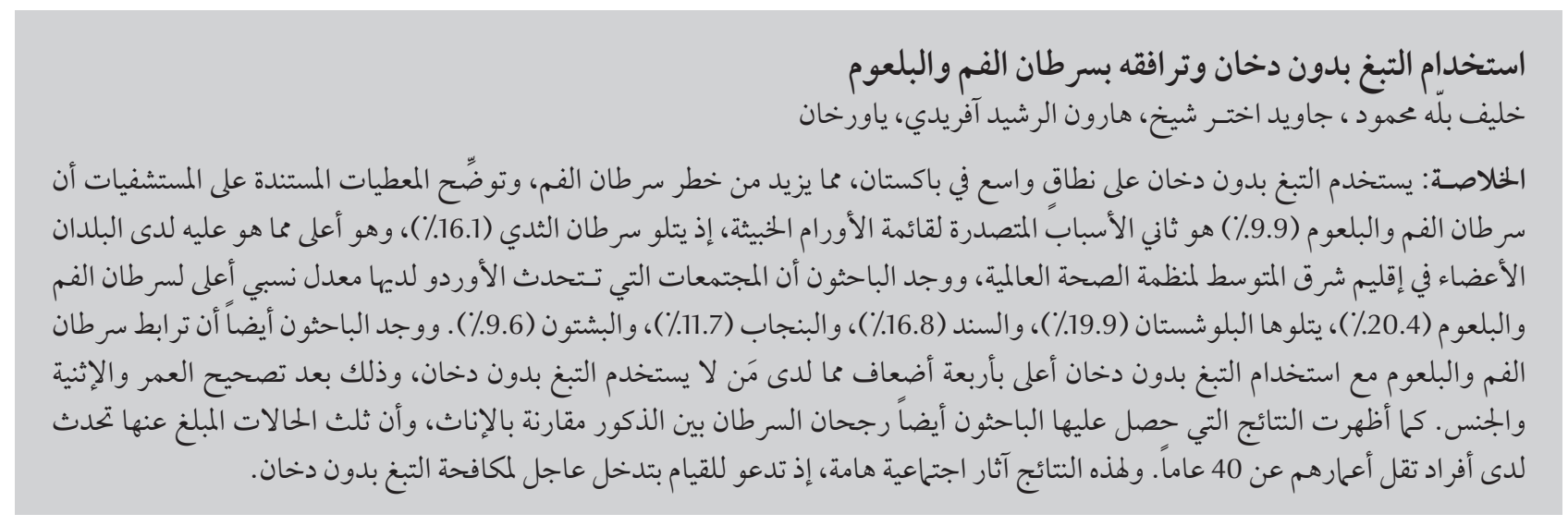

ABSTRACT Smokeless tobacco (ST), widely used in Pakistan, poses a high risk for oral cancer. Our hospital-based data illustrate that oropharyngeal cancer (9.9\%) is the second leading malignancy after breast cancer (16.1\%), and is significantly higher than in other Member States of the World Health Organization's Eastern Mediterranean Region. Urdu-speaking communities had a proportionately higher rate of oropharyngeal cancer (20.4\%), followed by Balochis (19.9\%), Sindhis (16.8\%), Punjabis (11.7\%) and Pashtuns (9.6\%). Association of oropharyngeal cancer with ST use was four times higher relative to no history of tobacco use after adjusting for age, ethnicity and gender. Our findings also show a predominance of this cancer among males relative to females and one-third of the reported cases occurred among individuals under 40 years. These findings have significant social impact, indicating the need for urgent intervention against the use of ST.

\section{Consommation de tabac sans fumée au Pakistan et association avec le cancer oropharyngé}

RÉSUMÉ Le tabac sans fumée, dont la consommation est largement répandue au Pakistan, induit un risque élevé de cancer de la cavité buccale. Les données obtenues auprès des hôpitaux montrent que le cancer oropharyngé est le deuxième cancer majeur $(9,9 \%)$ après le cancer du sein $(16,1 \%)$, avec un pourcentage nettement plus élevé que dans tout autre État Membre de la Région OMS de la Méditerranée orientale. Proportionnellement, les communautés parlant l'ourdou présentaient le taux de cancer oropharyngé le plus élevé (20,4\%), suivies par celles parlant le baloutchi $(19,9 \%)$, le sindhi $(16,8 \%)$, le pendjabi $(11,7 \%)$ et le pashto $(9,6 \%)$. Après ajustement des données en fonction de l'âge, de l'origine ethnique et du sexe, il a été constaté que les cancers oropharyngés étaient quatre fois plus fréquents chez les personnes qui consommaient du tabac sans fumée que chez celles qui n'avaient aucun antécédent de consommation de tabac. Nos résultats montrent également une prédominance de ce cancer chez les hommes. De plus, un tiers des cas signalés concernait des personnes de moins de 40 ans. Ces constats ont des répercussions sociales importantes et indiquent le besoin d'une intervention urgente contre la consommation de tabac sans fumée. 


\section{Introduction}

According to the World Health Organization (WHO), tobacco is the single most preventable cause of death in the world today [1]. It is estimated that 5.4 million deaths currently occur every year due to tobacco use [2] and projected figures show that by 2030 there will be more than 8 million deaths every year, of which $80 \%$ will take place in middle- and low-income developing countries $[1,2]$.

Tobacco can be used in different ways, ranging from cigarette, cigar and pipe smoking to smokeless products, available in various forms and mixtures. The most common forms of smokeless tobacco (ST) available and used in Pakistan include:

- Pan/betel with tobacco - a chewed mixture of areca nut (Areca catechu), tobacco, catechu (Acacia catechu) and slaked lime (calcium oxide and calcium hydroxide), wrapped in a betel leaf (Piper betel) with sweetening agents.

- Naswar - a mixture of sun-dried, sometimes only partially cured, powdered local tobacco (Nicotiana rustica), ash, oil, flavouring agents (e.g. cardamom, menthol), colouring agents (indigo) and lime.

- Chalia/supari - areca nut (used plain, flavoured with essences or coated with tobacco).

- Gutka - sun-dried roasted, finely chopped tobacco, areca nut, slaked lime and catechu mixed with flavours and sweeteners [3-6].

Most people place these forms of ST in the mandibular or labial groove or simply apply them to their teeth and gums and suck on them slowly for 10-15 minutes [7].

ST is highly addictive and is a highrisk factor for oropharyngeal cancers as well as cancers of the head and neck, oesophagus and pancreas [1]. The erroneous belief that chewing tobacco is a safe alternative to smoking may have led to this growing epidemic, despite the fact that it has multiple ill effects on human health [7].

Pakistan is one of the countries where the use of ST is a culturally acceptable habit. Various studies have reported the prevalence of chewing habits in different communities and locations. Studies from Karachi have shown that $21 \%$ of men and $12 \%$ of women use betel [7], for both men and women $7.3 \%$ use pan, $6.7 \%$ chalia, $7.5 \%$ gutka, $14.6 \%$ naswar [3] and use of betel and chewed tobacco is $20 \%$ and $17 \%$, respectively $[8,9]$. In medical students, the rate of ST use was reported as $6.4 \%$ [7], while among primary-school children, the use of areca and betel was $74 \%$ and $35 \%$, respectively [10].

Several studies have shown a clear independent link between the use of betel, areca and ST and oral submucous fibrosis, oral cancers, leukoplakia and other head and neck malignancies $[4,11]$. Among the Indian population, studies have estimated that $49 \%$ of oral cancers among males and 90\% among females are attributable to chewing habits [11]. A report from Pakistan has also shown that people using pan without tobacco and those using pan with tobacco were 9.9 and 8.4 times, respectively, more likely to develop oral cancer, after adjusting for covariates such as smoking, oral submucous fibrosis, use of alcohol and naswar [12]. Incidence rates of cancer of the oral cavity in both males and females were found to be among the highest in all urban cancer registries of south Asia relative to global data [4]. Similarly, cancers of the oral cavity and pharynx are highly common malignancies among males and females in Pakistan [13]. The age standardized incidence rate per 100000 population of oral cavity cancer in Karachi city from 1 January 1998 to 31 December 2002 was reported as 21.3 in males and 19.3 in females, considered to be among the highest in the world [14].

The objective of this retrospective hospital-based review was to assess the burden of oropharyngeal cancer among cancer patients admitted in key teaching and cancer hospitals in Pakistan, and evaluate the frequency and association of oropharyngeal cancer with the use of ST.

\section{Methods}

Datawereobtained from five majorleadinginstitutionsforcancerdiagnosticsand management in Pakistan, namely Shaukat Khanum Memorial Cancer Hospital \& Research Centre (SKMCH\&RC) in Lahore 2004-2007, Civil Hospital Karachi (CHK) 2004-2008, Jinnah Post Graduate Medical Centre (JPMC) in Karachi 2004-2008, Institute of Radiotherapy and Nuclear Medicine (IRNUM) in Peshawar 2005-2007, and Nuclear Medicine, Oncology and Radiotherapy Institute (NORI) in Islamabad 2006-2008. Only summarized data of 21245 cancer patients were obtained from SKMCH\&RC and NORI, showing ranking of the most frequently diagnosed cancers. Data of 29307 cancer patients, including information on use of ST and demographic details, were obtained from the Karachi hospitals CHK and JPMC and from IRNUM in Peshawar.

The assessed hospitals used different nomenclature to identify sites of different cancers. SKMCH\&RC classified malignancies based on the International Classification of Diseases for Oncology, 3rd Edition (ICD-O-3) code. NORI reported the most frequent cancers based on site-based categories, i.e. cancers of the breast, larynx, liver, oesophagus, lung, gastrointestinal tract (stomach, intestine, colon), blood cancers, cervix, oropharynx and others. Data from the Karachi and Peshawar hospitals outlined 50 different categories/sites of cancer, classifying malignancies as cancers of the breast, liver, oesophagus, pancreas, lung (lung, pleura, trachea, bronchi), gastrointestinal tract (stomach, small intestine, large intestine, 
colon), lymphoma (all types), leukaemia and multiple myeloma (all types), oropharynx (oral cavity and pharynx), larynx and others (all other organs, e.g. skin, genitourinary, soft tissue, bone, etc.). Oral cavity included the buccal mucosa, upper and loweralveolar ridges, floor of the mouth, retromolar trigone, hard palate, tongue and lips. Pharynx included oropharynx, nasopharynx and hypopharynx.

With regard to habits, patients were classified as: having a history of no addiction; using ST (i.e. pan, naswar, gutka, chalia/areca nut); smoking tobacco; using both ST and smoked tobacco; and those addicted to other substances, i.e. alcohol, bhang, opium, etc.

Permission was obtained from the hospitals, and a matrix was designed to generate retrospectively the cancer data available from these hospitals. Data were entered and analysed using SPSS, version 13.0.

Descriptive statistics of sociodemographic characteristics and use of ST were carried out using frequencies, while univariate and multivariate odds ratios (OR) with $95 \%$ confidence intervals (CI) were obtained using the chi-squared test and logistic regression analysis.

\section{Results}

Data from 50552 registered cancer patients were collected from five leading hospitals that manage cancer patients admitted for diagnosis and care during a period from 2004 to 2008 . Table 1 shows the sociodemographic characteristics of registered cancer patients in these five hospitals. Of these, 29307 patient records had demographic data, while only 7292 had data on tobacco use. The mean age of the cancer patients was 45 years at the time of diagnosis, ranging from 1 to 100 years.

Of the 29307 cancer patients with demographic data, $53 \%$ were males; ethnically, Pashtuns had more representation (55.5\%), while Baluchis and Punjabis were least represented in the study population (Table 1). The group categorized as "Other" included Bengalis, Uzbeks, Afghans, Marwaris and Gujaratis. Overall, there were significantly more users of ST (37.4\%) than tobacco smokers (23.6\%).

Aggregated data from 2004-2008 from the five sources showed that among the 50552 registered cases, breast cancer was the most common cancer (16.1\%), followed by oropharyngeal cancer (9.9\%), which was significantly higher than all other cancers $(P<0.001)$ (Table 2). When data were disaggregated by reporting hospital, oropharyngeal cancer was the most frequent cancer in JPMC and IRNUM, and was ranked second in $\mathrm{CHK}$, third in SKMCH\&RC and fifth in NORI.

Oropharyngeal cancer was significantly more frequent in Pakistan compared with the other countries from WHO's Eastern Mediterranean Region $(P<0.001)$ (Table 3).

In the univariate analysis, there was a significant linear trend of incremental rise in the prevalence of oropharyngeal cancer in the first 4 age groups ( $\chi^{2}$ test for linear trend, $P<0.01$ ) (Table 4). In the multivariate analysis, the association of oropharyngeal cancer with ST was also significantly more prominent among males than females (adjusted $\mathrm{OR}=1.59 ; 95 \% \mathrm{CI}: 1.438-1.82)$.

When controlling for ethnicity, age and sex, multivariate analysis showed that patients who used ST, smoked tobacco, or practised both habits, had a 4.7 (95\% CI: 3.92-5.54), 1.6 (95\% CI: $1.31-2.01)$ and 3.8 (95\% CI: (1.31-2.01) times higher likelihood, respectively, of having oropharyngeal cancer, when independently compared with patients not practising any of these habits and these were all statistically significant (Table 4).

Oropharyngeal cancer was significantly higher among native Urduspeaking and Balochi communities,

\begin{tabular}{|c|c|c|}
\hline \multicolumn{3}{|c|}{$\begin{array}{l}\text { Table } 1 \text { Social and demographic } \\
\text { characteristics of registered cancer } \\
\text { patients in five leading hospitals in } \\
\text { Pakistan }\end{array}$} \\
\hline Variable & No. & $\%$ \\
\hline \multicolumn{3}{|l|}{$\begin{array}{l}\text { Age at time of } \\
\text { diagnosis (years) }\end{array}$} \\
\hline$<25$ & 4374 & 14.9 \\
\hline $25-34$ & 2849 & 9.7 \\
\hline $35-44$ & 4813 & 16.4 \\
\hline $45-54$ & 6249 & 21.3 \\
\hline$\geq 55$ & 10986 & 37.5 \\
\hline Total & $29271^{a}$ & \\
\hline \multicolumn{3}{|l|}{ Sex } \\
\hline Male & 15529 & 53.0 \\
\hline Female & 13758 & 47.0 \\
\hline Total & $29287^{\mathrm{a}}$ & \\
\hline \multicolumn{3}{|l|}{ Ethnicity } \\
\hline Pashtun & 16256 & 55.5 \\
\hline Punjabi & 1035 & 3.5 \\
\hline Sindhi & 3019 & 10.3 \\
\hline Baluchi & 895 & 3.1 \\
\hline Urdu & 3606 & 12.3 \\
\hline Other & 4496 & 15.3 \\
\hline Total & 29307 & \\
\hline \multicolumn{3}{|l|}{ Habit } \\
\hline No addiction & 2514 & 34.5 \\
\hline Smokeless tobacco & 2730 & 37.4 \\
\hline Smoking tobacco & 1718 & 23.6 \\
\hline $\begin{array}{l}\text { Both (smoking and } \\
\text { smokeless) }\end{array}$ & 306 & 4.2 \\
\hline Other & 24 & 0.3 \\
\hline Total & $7292^{\mathrm{a}}$ & \\
\hline
\end{tabular}

${ }^{a}$ Data for 36 cases on age, 20 cases on sex and 22 015 cases on habit were not available.

relative to other ethnic groups while no such difference was found between these 2 groups (data not shown in tables). Moreover, Sindhis had a significantly higher oropharyngeal cancer rate relative to Punjabis, who in turn had a significantly higher oropharyngeal cancer rate compared to Pashtuns.

\section{Discussion}

The link between oropharyngeal cancer and consumption of betel, areca nut and tobacco chewing is well established, 


\begin{tabular}{|c|c|c|c|c|c|c|}
\hline Cancer & $\begin{array}{c}\text { JPMC } \\
\text { No. (\%) }\end{array}$ & $\begin{array}{c}\text { CHK } \\
\text { No. (\%) }\end{array}$ & $\begin{array}{l}\text { IRNUM } \\
\text { No. (\%) }\end{array}$ & $\begin{array}{c}\text { SKMCH \& RC } \\
\text { No. (\%) }\end{array}$ & $\begin{array}{l}\text { NORI } \\
\text { No. (\%) }\end{array}$ & $\begin{array}{c}\text { Total } \\
\text { No. }(\%)\end{array}$ \\
\hline Oropharynx & $1922(17.7)$ & $487(14.8)$ & $1444(9.5)$ & $796(6.3)^{b}$ & $395(4.60)$ & $5044(9.9)$ \\
\hline Breast & $1508(13.9)$ & $613(18.6)$ & $1392(9.2)$ & $2856(22.6)$ & $1790(20.9)$ & $8159(16.1)$ \\
\hline Liver & $361(3.3)$ & $110(3.3)$ & $176(1.2)$ & $725(5.7)$ & $142(1.65)$ & $1514(3.0)$ \\
\hline Larynx & $343(3.2)$ & $46(1.4)$ & $188(1.2)$ & - & $189(2.2)$ & 766 (1.5) \\
\hline Abdomen and anal canal & $698(6.4)$ & $320(9.7)$ & $898(5.9)$ & $540(4.3)^{c}$ & $1017(11.9)^{d}$ & $3473(6.9)$ \\
\hline Oesophagus & $496(4.6)$ & $117(3.5)$ & $1171(7.7)$ & - & $166(1.93)$ & $1950(3.9)$ \\
\hline Non-Hodgkin's lymphoma & $502(4.6)$ & $37(1.1)$ & $1312(8.7)$ & $908(7.2)$ & - & $2759(5.5)$ \\
\hline Hodgkin disease & - & - & - & $462(3.6)$ & - & $462(0.9)$ \\
\hline Lung & $798(7.3)$ & $183(5.5)$ & $479(3.2)$ & $399(3.2)$ & $422(4.92)$ & $2281(4.5)$ \\
\hline Brain & $265(2.4)$ & $21(0.6)$ & $851(5.6)$ & $257(2.0)$ & - & $1394(2.7)$ \\
\hline Skin & $180(1.7)$ & $26(0.8)$ & $830(5.5)$ & - & - & $1036(2.1)$ \\
\hline Uterus/ cervix & 366 (3.4) & $96(2.9)$ & 529 (3.5) & - & $197(2.3)^{\mathrm{e}}$ & $1188(2.4)$ \\
\hline $\begin{array}{l}\text { Acute lymphocytic } \\
\text { leukaemia }\end{array}$ & $125(1.1)$ & $2(0.1)$ & $748(4.9)$ & $281(2.2)$ & - & $1156(2.3)$ \\
\hline Leukaemia & - & - & - & $401(3.2)$ & $730(8.5)^{f}$ & $1131(2.2)$ \\
\hline Others & 3322 (30.5) & $1241(37.6)$ & $5104(33.8)$ & 5039 (39.8) & $3533(41.2)$ & 18239 (36.1) \\
\hline Total & 10886 & 3299 & 15122 & 12664 & 8581 & 50552 \\
\hline
\end{tabular}

${ }^{a}$ Nomenclature variance is related to the use of different classification by the different centres.

${ }^{b}$ Oral cavity.

'Colorectal.

${ }^{d}$ Gastrointestinal (all other).

${ }^{e}$ Cervix.

${ }^{f}$ Blood cancers.

CHK = Civil Hospital Karachi; IRNUM = Institute of Radiotherapy and Nuclear Medicine; JPMC = Jinnah Post Graduate Medical Centre; NORI = Nuclear Medicine, Oncology and Radiotherapy Institute; SKMCH \&RC = Shaukat Khanum Memorial Cancer Hospital \& Research Centre.

and the habit is a commonly accepted cultural practice in south Asia $[3,4]$. The demographic profile of the diagnosed cancer patients in this study represents a multi-ethnic group of Pakistan as it includes five major leading institutions for cancer diagnostics and management from different parts of the country.

Since the ratification of the WHO Framework Convention on Tobacco Control (WHO FCTC) in 2005, the fight against tobacco use and cigarette smoking in particular has become an area of major public health debate in $\mathrm{Pa}$ kistan, where the government, civil society organizations and media attempt to control tobacco use in the country. On the other hand, tobacco manufacturers have reignited fierce opposition to these national efforts. Pakistan, the sixth most populous nation in the world, has a high tobacco consumption rate; however, tobacco cultivation is a primary cash crop in one province (Khyber Pakhtunkhwa) and this has brought political sensitivity to this important debate. Moreover, the Government interpretation of the WHO FCTC and the proposed control interventions were almost exclusively directed towards the control of cigarette smoking, while the control of ST was ignored. As in most south Asian countries, the use

\begin{tabular}{|c|c|c|c|c|c|c|c|c|}
\hline \multirow[t]{2}{*}{ Country } & Total & Oropharynx & $\begin{array}{c}\text { Stomach, } \\
\text { colon, rectum }\end{array}$ & Liver & Pancreas & Larynx & Lungs & Oesophagus \\
\hline & & No. (\%) & No. (\%) & No. (\%) & No. (\%) & No. (\%) & No. (\%) & No. (\%) \\
\hline Lebanon [19] & 7888 & $111(1.41)$ & 839 (10.64) & $67(0.85)$ & $120(1.52)$ & $135(1.71)$ & 875 (11.09) & - \\
\hline Jordan [21] & 3142 & 75 (2.39) & 385 (12.25) & $74(2.36)$ & $27(0.86)$ & $50(1.59)$ & $211(6.72)$ & $27(0.86)$ \\
\hline Kuwait [22] & 584 & $15(2.57)$ & $69(11.82)$ & $13(2.23)$ & $12(2.05)$ & $5(0.86)$ & $44(7.53)$ & $4(0.68)$ \\
\hline $\begin{array}{l}\text { Islamic Republic of } \\
\text { Iran [20] }\end{array}$ & 47217 & 1206 (2.55) & 8616 (18.25) & $283(0.6)$ & $211(0.45)$ & 785 (1.66) & 1506 (3.19) & $2584(5.47)$ \\
\hline Pakistan & 50552 & $5044(9.90)$ & 3473 (6.90) & $1514(3.0)$ & $218(0.43)$ & $766(1.50)$ & $2281(4.50)$ & 1950 (3.90) \\
\hline
\end{tabular}




\begin{tabular}{|c|c|c|c|c|c|}
\hline \multirow[t]{2}{*}{ Variable } & \multirow[t]{2}{*}{ All cases } & \multicolumn{2}{|c|}{ Oropharyngeal cancer } & \multirow[t]{2}{*}{ Crude OR $(95 \% \mathrm{Cl})$} & \multirow[t]{2}{*}{ Adjusted OR $(95 \% \mathrm{CI})^{\mathrm{a}}$} \\
\hline & & No. & (\%) & & \\
\hline \multicolumn{6}{|c|}{ Age at time of diagnosis (years) } \\
\hline$<25$ & 4374 & 395 & 9.0 & 1 & 1 \\
\hline $25-34$ & 2849 & 349 & 12.2 & $1.40(1.2-1.63)$ & $2.6(1.7-4.05)$ \\
\hline $35-44$ & 4813 & 689 & 14.3 & $1.68(1.47-1.91)$ & $3.5(2.4-5.2)$ \\
\hline $45-54$ & 6249 & 943 & 15.1 & $1.79(1.58-2.02)$ & $3.4(2.3-5.0)$ \\
\hline$\geq 55$ & 10986 & 1470 & 13.4 & $1.55(1.38-1.74)$ & $2.6(1.8-3.8)$ \\
\hline Total & 29271 & 3846 & 13.1 & & \\
\hline \multicolumn{6}{|l|}{ Sex } \\
\hline Female & 13758 & 1466 & 10.7 & 1 & 1 \\
\hline Male & 15529 & 2384 & 15.4 & $1.52(1.42-1.63)$ & $1.59(1.38-1.82)$ \\
\hline Total & 29287 & 3850 & 13.1 & & \\
\hline \multicolumn{6}{|l|}{ Habit of patient } \\
\hline No addiction & 2514 & 207 & 8.2 & 1 & 1 \\
\hline Smokeless tobacco & 2730 & 867 & 31.8 & $5.1(4.4-6.1)$ & $4.66(3.92-5.54)$ \\
\hline Smoke tobacco & 1718 & 281 & 16.4 & $2.1(1.8-2.6)$ & $1.62(1.31-2.01)$ \\
\hline Both & 306 & 92 & 30.1 & $4.7(3.6-6.3)$ & $3.77(2.80-5.08)$ \\
\hline Others & 24 & 3 & 12.5 & $1.5(0.4-5.3)$ & $1.04(0.30-3.56)$ \\
\hline Total & 7292 & 1450 & 19.9 & & \\
\hline \multicolumn{6}{|l|}{ Ethnicity } \\
\hline Pashtun & 16256 & 1553 & 9.6 & 1 & 1 \\
\hline Punjabi & 1035 & 121 & 11.7 & $1.25(1.03-1.53)$ & $2.19(1.58-3.04)$ \\
\hline Sindhi & 3019 & 508 & 16.8 & $1.92(1.72-2.13)$ & $3.05(2.37-3.92)$ \\
\hline Balochi & 895 & 178 & 19.9 & $2.35(1.98-2.79)$ & $3.03(2.23-4.13)$ \\
\hline Urdu speaking & 3606 & 734 & 20.4 & $2.42(2.20-2.67)$ & $3.12(2.47-3.93)$ \\
\hline Others & 4496 & 759 & 16.9 & $1.92(1.75-2.11)$ & $2.61(2.05-3.32)$ \\
\hline Total & 29307 & 3853 & 13.1 & & \\
\hline
\end{tabular}

${ }^{a}$ Adjusted for the other variables shown in the table. $C I=$ confidence interval; $O R=$ odds ratio.

of ST products is a common practice in Pakistan, although predominantly limited to the lower socioeconomic strata of the population, except for the occasional traditional use of these products, particularly pan, in local groups, especially in Sindh province [3,7]. The evident lack of regulatory attention may be attributed to the strong traditional base of the habit, the low social status of its prime consumers, the limited use of these substances in more prominent public places, the lack of taxation interest by the Government, and insufficient awareness and knowledge about the health hazards and risks associated with these products $[3,6]$.
Our analysis illustrates that oropharyngeal cancer was the second most prevalent malignancy in Pakistan, reflecting the high burden collectively experienced by most provincial cancer diagnostic and management centres [14-16]. When data from these sources were disaggregated, this cancer was the most frequent in 2 of the source centres, was ranked second and third in 2 other source centres and was fifth in the remaining source, indicating the robustness of these findings. However, it is important to note that an earlier study of the 10 most frequent cancers globally ranked mouth and pharynx cancer as the sixth most frequent cancer in the world [17], while a later study did not include oropharyngeal cancer in the 10 most frequent cancers in both developed and developing countries [18]. Oropharyngeal cancer was also significantly more frequent in Pakistan relative to several other countries in the Region with available data [19-22]. Our findings therefore reveal a distinct regional public health problem, requiring urgent action by the Pakistan Government.

Among the patients whose exposure to tobacco risk was recorded, there was a significant association between oropharyngeal cancer and ST use; in fact twice as strong as that between 
oropharyngeal cancer and cigarette smoking, reflecting the burden that this habit inflicts on the population's health. This association is explained by WHO's recent confirmation of the presence of at least 28 carcinogens in ST, including non-volatile alkaloid-derived tobacco, specific nitrosamines, $N$-nitrosamines, inorganic compounds such as arsenic and nickel, plus radio-elements such as polonium, uranium, beryllium and others [5].

Although in both males and females, ST use was significantly associated with oropharyngeal cancer, male patients had almost a $60 \%$ higher risk of developing the disease than females. The significant incremental linear trend in the prevalence of oropharyngeal cancer in the first 4 age group categories of the study population illustrates the potential cumulative impact of the use of ST, an epidemiological observation corroborated by previous studies $[5,14]$. The association of oropharyngeal cancer with ST was significantly higher for both males and females relative to nonST users, although this relationship was more prominent among males. With the mean age of the patients being 45 years, a profound socioeconomic burden may be attached to the premature mortality likely to result from such early age diagnosis, indicating the need for control interventions linking the prevention of ST use to the ongoing national action against tobacco use.
The observed greater occurrence of oropharyngeal cancer among native Urdu-speaking and Balochi patients relative to other ethnic groups in the country may be explained by the different sociocultural traditions related to ST use [13,23]. In Pakistan, the chewed forms of ST, pan and gutka, are presumed to be more common among the Urdu-speaking and Balochi communities, especially those living in Sindh province, while the relatively lower occurrence of the disease in individuals from other groups may be attributed to a relatively lower consumption of these chewable ST products [23]. However, this assumption is not conclusive, considering the limitations of the study, as the 2 hospitals in Lahore and Islamabad did not have demographic data on ethnicity or records on the habitués of tobacco. Moreover, the 7292 cases for which information on tobacco use was available had no account of the duration of exposure that could have an impact on the disease occurrence. According to the Pakistan Tobacco Board, the total production of tobacco for 2006-2007 was 103000 tons, of which about 50\% was used for cigarette manufacturing, while the remaining quantity may have been used in ST forms. In addition, exported and imported quantities were comparable, each being estimated at $5 \%$ of the yearly production [24].

Pakistan has to reinforce its political and public health efforts to control this preventable killer and build an alliance between the ministries of health, education, commerce, agriculture, the Central Board of Revenue and the provincial governments to ban all forms of tobacco advertisement, sponsorship and marketing, ban all forms of tobacco consumption in all public places and increase the excise taxes on all forms of tobacco. A national cancer registry should also be established to generate an account of the incidence trends, the patterns and burden in the country, the population at risk, and the risk factors engaged, especially smokeless tobacco use. Such a knowledge base will facilitate the introduction of control interventions that consider the underlying social, economic and cultural factors and render the prevention of oral cancer an integral part of the national cancer control programme.

\section{Acknowledgement}

The authors thank the management of the 5 hospitals: Civil Hospital Karachi; Institute of Radiotherapy and Nuclear Medicine; Jinnah Post Graduate Medical Centre; Nuclear Medicine, Oncology and Radiotherapy Institute and Shaukat Khanum Memorial Cancer Hospital \& Research Centre, who made their cancer data available for this study.

\section{References}

1. WHO report on the global tobacco epidemic, 2008; the MPOWER package. Geneva, World Health Organization, 2008.

2. Mathers CD, Loncar D. Project of global mortality and burden of disease from 2002 to 2030. PLoS Medicine, 2006, 3(11):e442.

3. Khawaja MRH et al. Chewing of betel, areca and tobacco: perceptions and knowledge regarding their role in head and neck cancers in an urban squatter settlement in Pakistan. Asian Pacific Journal of Cancer Prevention, 2006, 7:95-99.

4. Nair U, Bartsch H, Nair J. Alert for an epidemic of oral cancer due to use of the betel quid substitutes gutkha and pan masala: a review of agents and causative mechanism. Mutagenesis, 2004, 19(4):251-261.
5. IARC monographs on the evaluation of carcinogenic risks to humans. Volume 89: Smokeless tobacco and some tobacco-specific $\mathrm{N}$-nitrosamines. Lyon, World Health Organization, International Agency for Research on Cancer, 2007.

6. Gupta PC, Ray C S. Smokeless tobacco and health in India and South Asia. Respirology, 2003 8:419-431.

7. Imam $\mathrm{S} Z$ et al.Use of smokeless tobacco among groups of Pakistani medical students - a cross sectional study. BMC Public Health, 2007, 7:231.

8. Mahmood Z. Smoking and chewing habits of people in Karachi 1981. Journal of Pakistan Medical Association, 1982, 32:34-37. 
9. Qidwai W et al. Are our people health conscious? Results of a patient survey in Karachi, Pakistan. Journal of Ayub Medical College Abottabad, 2003, 15(1):10-13.

10. Shah SM et al. Addicted school children: prevalence and characteristics of areca nut chewers among primary school children in Karachi, Pakistan. Journal of Paediatric and Child Health, 2002, 38:507-510.

11. Balaram P et al. Oral cancer in Southern India: the influence of smoking, drinking paan-chewing and oral hygiene. International Journal of Cancer, 2002, 98:440-445.

12. Marchant A et al. Paan without tobacco: an independent risk factor for oral cancer. International Journal of Cancer, 2000, 86:128-131.

13. Bhurgri $Y$ et al. Cancer of the oral cavity and pharynx in Karachi - identification of potential risk factors. Asian Pacific Journal of Cancer Prevention, 2003, 4:125-130.

14. Bhurgri Y. Cancer and the oral cavity - trends in Karachi South (1995-2002). Asian Pacific Journal of Cancer Prevention, 2005, $6: 22-26$.

15. Bhurgri $Y$ et al. Cancer profile of Hyderabad, Pakistan (19982002). Asian Pacific Journal of Cancer Prevention, 2005, 6:474480.

16. Bhurgri Y et al. Cancer profile of Larkana, Pakistan (2000-2002). Asian Pacific Journal of Cancer Prevention, 2006, 7:518-521.
17. Parkin DM, Pisani P, Ferlay J. Estimates of the worldwide incidence of eighteen major cancers in 1985. International Journal of Cancer, 1993, 54:594-606.

18. Mackay J et al., eds. The cancer atlas. Brighton, American Cancer Society, 2006.

19. Salim M, Adib MD, Daniel J, eds. National cancer registry: cancer in Lebanon 2003. Beirut, Ministry of Public Health, 2003.

20. Mousavi SM, ed. Report of national cancer registration in Iran 2004-2005. Tehran, Ministry of Health and Medical Education, 2006.

21. Al-Kayed S, Hijawi B, eds. National cancer registry: incidence of cancer in Jordan. Amman, Ministry of Health, 1999

22. Al-Hattab O, ed. Kuwait cancer registry: annual report 2003. Kuwait, Ministry of Health, 2003.

23. Mazahir S et al. Socio demographic correlates of betel, areca and smokeless tobacco use as a high risk behavior for head and neck cancers in a squatter settlement of Karachi, Pakistan. Substance Abuse, Treatment, Prevention, and Policy, 2006, 1:10).

24. Tobacco statistical bulletin 2007. Peshawar, Pakistan Tobacco Board, Ministry of Commerce, 2007. 